\title{
The Relevance between Iodine Nutritional Status and BRAFV600E Mutation on Papillary Thyroid Cancer
}

\author{
Yan-Yu Lin ${ }^{1}$ and Yu-Shan Hsieh ${ }^{2, *}$ \\ 1 Division of Endocrinology and Metabolism, Department of Internal Medicine, Taipei Medical University \\ Hospital, Taipei City 11031, Taiwan; vincent_elva@hotmail.com \\ 2 School of Nursing, National Taipei University of Nursing and Health Sciences, Taipei City 11230, Taiwan; \\ yushan@ntunhs.edu.tw \\ * Correspondence: yushan@ntunhs.edu.tw; Tel.: +886-2-2822-7101
}

\begin{abstract}
Papillary thyroid carcinoma (PTC) accounts for approximately $85 \%-90 \%$ of all thyroid cancers. BRAFV600E mutation is a highly specific target for papillary thyroid carcinoma (PTC) and may have a reciprocal causative relationship with iodide-metabolizing genes. Here, we performed a review of studies published in the past 10 years to determine the relationship between iodine intake and BRAFV600E mutation in patients with PTC. We searched the MEDLINE, PubMed, and EMBASE databases for studies published from 2009 to 2019; seven partially matched the selection criteria and were suitable for review, and five passed all selection criteria. We divided the patients into three groups by iodine intake: low (urinary iodine concentration [UIC] $<100 \mu \mathrm{g} / \mathrm{L}$ ), adequate (UIC 100-200 $\mu \mathrm{g} / \mathrm{L}$ ), and high iodine intake groups (UIC $\geq 200 \mu \mathrm{g} / \mathrm{L}$ ). Between-group analysis revealed no significant differences in the odds ratio of the prevalence of BRAFV600E mutation between the high and adequate/low iodine intake groups and between the adequate and low iodine intake groups. To further analyzed the results of studies, they exhibited U-shaped curves in the relation of deficient and excessive dietary iodine intake in BRAFV600E mutation. The results might suggest that iodine intake slightly influences the prevalence of BRAFV600E mutation in patients with PTC despite the heterogeneity of studies. Further research should explore potential mechanisms underlying the associations between iodine intake and BRAF mutation in PTC. The systematic review was registered in PROSPERO (CRD42021279462).
\end{abstract}

Keywords: iodine nutritional status; BRAFV600E; papillary thyroid cancer

\section{Introduction}

Papillary thyroid carcinoma (PTC) accounts for approximately $85 \%-90 \%$ of all thyroid cancers [1]. The b-raf oncogene (BRAF) mutation caused by thymine-to-adenine transversion is the major oncogenic genetic alteration and a highly specific target for PTC, whereas the valine-to-glutamic acid mutation (BRAFV600E) is the most prevalent. A Korean study reported that patients with the BRAFV600E mutation who received treatment exhibited a higher frequency of the more aggressive pathological features of PTC [2]. Iodine is involved in whether BRAFV600E mutation between normal and tumor tissues, which might provide crucial information on tumorigenesis. Relatively low and extremely high iodine intakes are associated with an increased probability of thyroid cancer [3]. Given that BRAFV600E mutation and iodide-metabolizing genes may have a reciprocal causative relationship, it is necessary to consider the association between changes in iodine intake and expression of related downstream genes in a population.

Taiwan was an iodine-deficient area and implemented a mandatory salt iodization policy from 1971 to 2002 [4]. However, compared with the results of The Nutrition and Health Survey in Taiwan 2005-2008 and 2013 [5], the urinary iodine concentration (UIC) of citizens (aged $<44$ years) were not higher during the supplementary salt fortification 
period, which indicated that the Taiwanese dietary style is changing [6]. However, a study in 1999-2009 [1] , revealed a high prevalence (73\%) of the BRAFV600E gene mutation in conventional PTCs, which was considerably higher than prior evidence (47\%) in 1997-2002 [7] and similar to that reported in South Korea (73.7\%), an iodine-replete area [2]. An epidemiological study in South Korea reported that relatively low UIC $(<300$ $\mu \mathrm{g} / \mathrm{L})$ and extremely high UIC $(\geq 500 \mu \mathrm{g} / \mathrm{L})$ were both significant risk markers for BRAFV600E mutations in the thyroid [3]. These data indicate that it is necessary to consider not only changes in dietary iodine intake but also the association between these changes and related downstream gene expression in patients with PTC.

However, the relationship between iodine intake and BRAFV600E mutation in PTC remains controversial and unclear. Therefore, we performed a systemic review of available epidemiological studies in the past 10 years to determine the relationship between iodine intake and the prevalence of BRAF mutation in patients with PTC. Various studies discussed the relation between the prevalence of BRAF and PTC, but there are few studies of relation between iodine nutrition status and prevalence of BRAF in PTC. The purpose of this study is to understand the importance of iodine nutrition status in PTC patient and clarify whether lower or higher iodine nutritional status in to regulate BRAF V600E mutation.

\section{Materials and Methods}

\subsection{Protocol and registration}

The review protocol was designed in line with the PRISMA guidelines and registered in The International Prospective Register of Systematic Reviews (PROSPERO), the project identification code is CRD42018088210. Because the review article generally does not need ethics committee or institutional review board approval.

\subsection{Eligibility criteria}

Inclusion and exclusion criteria were defined at the time of study conception and before data collection. Studies were included if the following criteria were met:

- Design: Comparative studies that were randomized controlled trials (RCTs; clinical trials in which the participants are randomized to different treatment groups) or non-RCTs (where participants are not randomized to different treatment groups) published as a full-length article in English in a peer-reviewed journal between June 2009 and June 2019.

- Participants: Patients with PTC.

- Interventions /exposure: Different level of Iodine nutritional status was the main exposure. Patients were stratified by iodine intake, which was determined using urinary iodine concentration (UIC). Low (UIC $<100 \mu \mathrm{g} / \mathrm{L}$ ), and high iodine intake groups (UIC $\geq 200 \mu \mathrm{g} / \mathrm{L}$ ).

- Comparison: Adequate UIC of PTC patients (UIC 100-200 $\mu \mathrm{g} / \mathrm{L}$ ).

- Outcome: Prevalence of BRAF mutation

We excluded studies without (1) definition of dietary iodine intake, (2) patients with PTC, and (3) comparison groups. Studies included in the analysis were reviewed for the following characteristics: author and year of publication, language of publication, and definition of iodine intake. 


\subsection{Literature selection}

Two independent researchers searched the MEDLINE, PubMed and EMBASE databases for English language articles from inception to June 2020 using the following terms: "iodine," "BRAFV600E," and "PTC" or "papillary thyroid cancer." A total of 102 potential articles published between 2009 and 2020 were identified, and their abstracts were reviewed. Figure 1 presents the PRISMA flow chart of study selection.

\subsection{Definition of iodine intake}

Median UIC is the most commonly used indicator of population iodine nutrition. To determine the UIC as a population-level indicator of iodine status was also recommend by The World Health Organization (WHO). 29 articles were selected on the basis of their abstracts, and a holistic review of the text was performed. The 7 articles including a part of matched the selection criteria and were suitable for meta-analysis. Finally, 5 articles passed criteria which including 2086 patients (UIC $<100$ microgram per liter $[\mu \mathrm{g} / \mathrm{L}]$ group=553, UIC $100-200 \mu \mathrm{g} / \mathrm{L}$ group $=772$, UIC $>200 \mu \mathrm{g} / \mathrm{L}$ group=761), respectively. According to the $\mathrm{WHO}$, the levels of dietary iodine intake based on UIC are as follows: low dietary iodine (LI; UIC $<100 \mu \mathrm{g} / \mathrm{L}$ ), adequate dietary iodine (AD; UIC 100-200 $\mu \mathrm{g} / \mathrm{L}$ ), and high dietary iodine (HI; UIC $\geq 200 \mu \mathrm{g} / \mathrm{L}$ ).

\subsection{Data collection process}

Two independent researchers extracted the following data from the articles: author, year, participant population, participant sample size, age, iodine intake, comparison group, and outcomes.

\subsection{Summary measures}

To quantify and summarize our data, if all eligible trials measured an outcome using the same metric, we used the odds ratio (OR) for the prevalence of BRAFV600E mutation in a particular group of iodine intake level to analyze our results.

\subsection{Synthesis of results}

We compared the prevalence of BRAFV600E mutation between groups with different levels of iodine intake. The OR and 95\% confidence interval (CI) were the statistical effect size used to estimate the effect of exposures. The I2 test was used to quantify heterogeneity. All statistical analyses were performed using the Review Manager version 5.3.5 (RevMan for Windows, 2015; The Cochrane Collaboration, Oxford, UK). If I2 indicated high heterogeneity (I2 $>50 \%$ ) between the studies, the random-effect model was selected; $\mathrm{p}<0.05$ was considered statistically significant.

For further analyses our result, we used between -group analysis to look at the study results about the groups. The method could point out how BRAFV600E mutation change of different iodine nutritional status groups. 


\subsection{Statistical analysis}

Results are presented as means \pm standard deviation (SD). The results of BRAF mutation prevalence $(\%)$ of studies were analyzed by one-way analysis of variance (ANOVA), and other variables were compared by one-way ANOVA followed by an LSD post hoc test using SPSS Statistics22 version (IBM, USA). A P-value $<0.05$ was considered statistically significant.

\section{Results}

A total of 102 articles were retrieved from the databases. We selected 29 articles on the basis of their abstracts, and a holistic review of the text was performed. After excluding unqualified articles, seven articles were partially consistent with the criteria. Finally, five studies with a total of 2086 patients with PTC with different levels of dietary iodine intake $(\mathrm{UIC}<100 \mu \mathrm{g} / \mathrm{L}$ group $=553$, UIC 100 $-200 \mu \mathrm{g} / \mathrm{L}$ group $=772, \mathrm{UIC} \geq 200 \mu \mathrm{g} / \mathrm{L}$ group $=$ 761) were included (Figure 1). Five studies were based on the study of PTC patients with different level of iodine dietary intake, and two studies were excluded because they lacked iodine intake data or comparison groups [12]. Table 1 summarizes the characteristics of the included studies.

\subsection{Between-group analysis of prevalence of BRAFV600E mutation between different level of UIC}

First, we analyzed the prevalence rate of the BRAFV600E between HI status (UIC $\geq 200$ $\mu \mathrm{g} / \mathrm{L}$ ) and relative AD status (UIC $<200 \mu \mathrm{g} / \mathrm{L}$ ) group. The OR of the prevalence of BRAFV600E mutation between two levels of UIC in patients with PTC was 1.25 (95\% CI $0.64-2.43$, Fig. 2A). In the presented results of the UIC $\geq 200 \mu \mathrm{g} / \mathrm{L}$ group, the OR of BRAFV600E mutation was not significantly different to that of the UIC $<200 \mu \mathrm{g} / \mathrm{L}$ group $(\mathrm{p}=0.51)$ of patients with PTC.

Based on the results, we subsequently analyzed the prevalence rate of the BRAFV600E gene mutation between LI status (UIC $<100 \mu \mathrm{g} / \mathrm{L}$ ) and AD status (UIC $\geq 100 \mu \mathrm{g} / \mathrm{L}$ and $\leq 200 \mu \mathrm{g} / \mathrm{L})$. The OR of the prevalence of BRAFV600E mutation between different LI and AD statuses in patients with PTC was 0.98 (95\% CI 0.42-2.31, Figure 2B), and no significant difference $(\mathrm{p}=0.96)$ existed in patients between the two groups. The heterogeneity of the data that I2 estimated the variance between the studies was $71 \%$ in Figure $2 \mathrm{~A}$ and $91 \%$ in Figure 2B. The heterogeneity I2 estimate of the variance between the studies was $92 \%$, mainly from the study by Kim el al. [3]. However, the I2 test of heterogeneity revealed a considerable level of heterogeneity in the risk estimates.

Based on the results that showed relatively high heterogeneity between articles, for further evaluation we analyzed the prevalence of BRAFV600E mutation under high, adequate, and low iodine intakes separately.

\subsection{Statistical analysis of prevalence of BRAFV600E mutation in different level of UIC}

We performed statistical analyses by different levels of UIC. Five articles were initially included in the different iodine intake status. The BRAF mutation risk was no significantly changed under different iodine nutrition status $(p=0.3288)$. However, the results of studies exhibited U-shaped curves in the relation of deficient and excessive dietary iodine intake in BRAFV600E mutation (Figure 3). 
3.3. Figures and Tables

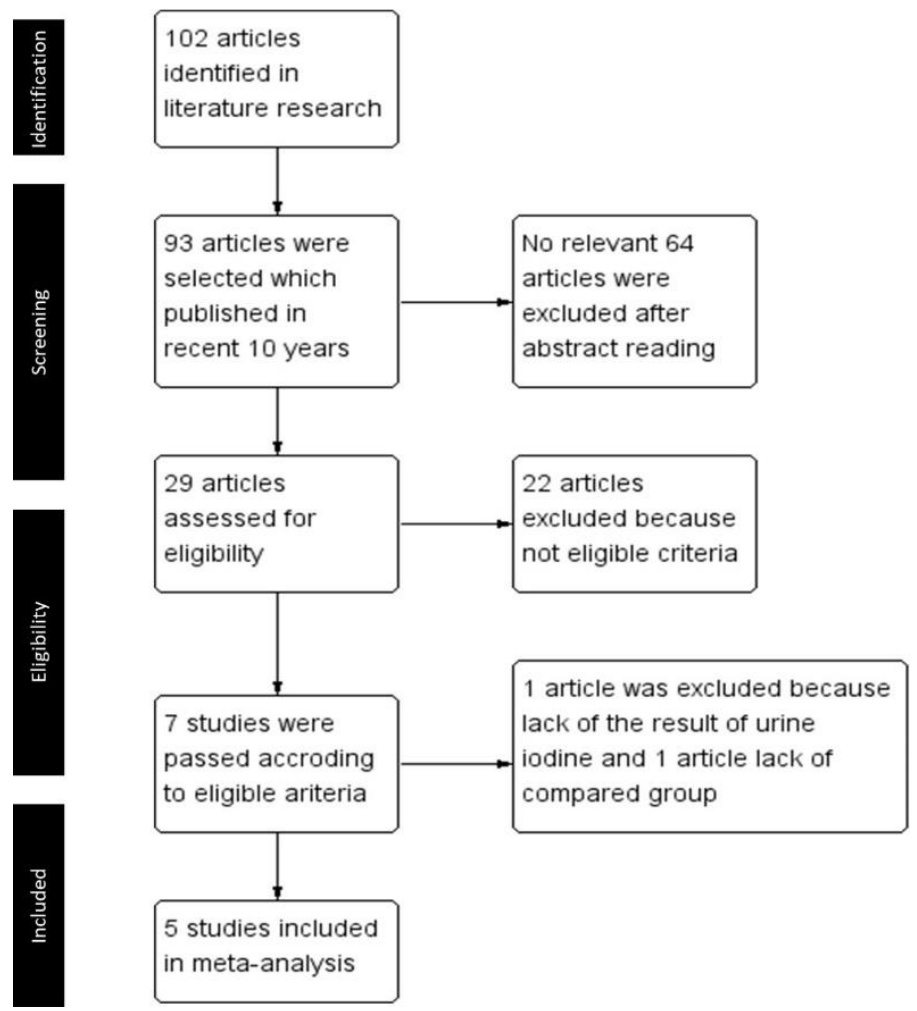

Figure 1. Flow chart of the selection of eligible studies (Preferred reporting items for systematic reviews and meta-analyses [PRISMA]).

Table 1. Summary of included studies.

\begin{tabular}{|c|c|c|c|c|c|}
\hline $\begin{array}{c}\text { Authors } \\
\text { (Country, year) }\end{array}$ & Study type & Patients (n) & $\begin{array}{c}\text { Age } \\
\text { (mean) }\end{array}$ & $\begin{array}{c}\text { Criteria of UIC } \\
\qquad(\mu \mathrm{g} / \mathrm{L})\end{array}$ & $\begin{array}{l}\text { BRAFV600E } \\
\text { mutation(\%) }\end{array}$ \\
\hline Guan & Non-RCT & HI:559 & 43.59 & $\geqq 900^{\mathrm{a}}$ & $387 / 559(69)$ \\
\hline \multirow[t]{3}{*}{ (China,2009 ${ }^{[8]}$ ) } & & $\mathrm{AD} 1: 240$ & & $188^{\mathrm{a}}$ & $128 / 240(53)$ \\
\hline & & $\mathrm{AD} 2: 76$ & & $198^{\mathrm{a}}$ & $38 / 76(50)$ \\
\hline & & AD3:157 & & $82.77^{\mathrm{a}}$ & $86 / 157(55)$ \\
\hline Voung & Non-RCT & HI:67 & 49.3 & $\geqq 281^{\mathrm{b}}$ & $55 / 67(82)$ \\
\hline (Japan, Vietnam, $2016^{[9]}$ ) & & LI:53 & 43.5 & $56^{\mathrm{b}}$ & $44 / 53(83)$ \\
\hline Kim & Non-RCT & VHI:75 & 46 & $\geqq 500$ & $64 / 75(85)$ \\
\hline \multirow[t]{4}{*}{ (Korea,2018 ${ }^{[3]}$ ) } & & $\mathrm{HI}: 27$ & 48 & $300-499$ & $15 / 27(56)$ \\
\hline & & $\mathrm{AD}: 33$ & 46 & $200-299$ & $28 / 33(85)$ \\
\hline & & RL:49 & 45 & $100-199$ & $40 / 49(82)$ \\
\hline & & LI:31 & 44 & $\leqq 100$ & $26 / 31(84)$ \\
\hline Pellegriti & Non-RCT & AD:106 & $\mathrm{N}$ & ISA $(113.8 \pm 8.4)^{\mathrm{c}}$ & $68 / 205(33)$ \\
\hline (Italy, $2009^{[10]}$ ) & & LI:205 & & $\operatorname{IDA}(18.9 \pm 4.1-43.2 \pm 4.9)^{\mathrm{c}}$ & $55 / 106(52)$ \\
\hline Liu & Non-RCT & HI:202 & $\mathrm{N}$ & $\operatorname{High}(198)^{\mathrm{d}}$ & $148 / 202(73)$ \\
\hline (China, $2014^{[11]}$ ) & & AD:206 & & Normal $(82.77)^{\mathrm{d}}$ & $102 / 206(50)$ \\
\hline Lee & Single group & HI:210 & $43.4-45.1$ & Mutation (+): 884 & $169 / 210(89)$ \\
\hline$\left(\text { Korea,2018 }{ }^{[12]}\right)^{\mathrm{e}}$ & study & & & Mutation (-):792.9 & \\
\hline
\end{tabular}


RCT, Randomized Controlled Trial; VHI, very high iodine intake group; HI, high iodine intake group; $\mathrm{AD}$, adequate iodine intake group; $\mathrm{RL}$, relatively low iodine intake group; LI, low iodine intake group; N, Not obtained.

a The level of UIC base on the mean UIC from the population in the area. AD1 group is the population from Shenyang, China (Median UIC is $188 \mu \mathrm{g} / \mathrm{L}$ ), AD2 group is the population from Shanghai, China (Median UIC is $198 \mu \mathrm{g} / \mathrm{L}$ ) and AD3 group is the population from Qingdao, China (Median UIC is $82.77 \mu \mathrm{g} / \mathrm{L}$ ).

bThe level of UIC in Vietnamese and Japanese based on previously study [13, 14].

ISA and IDA(iodine sufficient area and iodine-deficient area, the level of UIC is based on previous study) [15].

${ }^{\mathrm{d}}$ High and normal intake area, the level of UIC based on previously study [8].

eReference 12 is excluded the reference in present study because of the single group study which have no compared population.

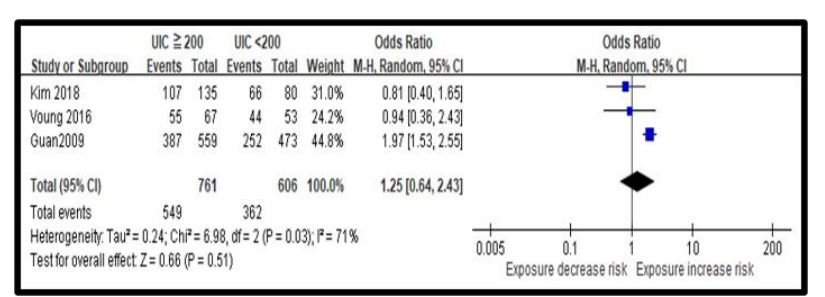

(a)

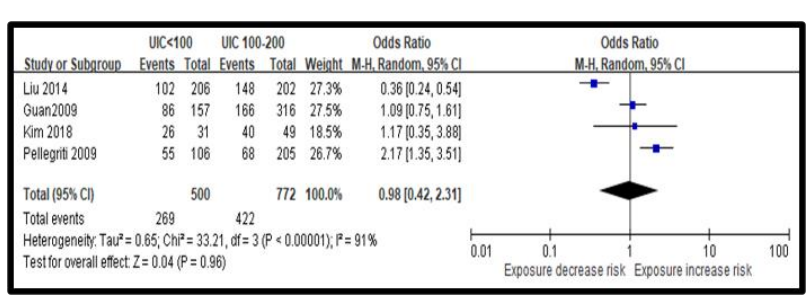

(b)

Figure 2. The prevalence of BRAFV600E mutation among different levels of iodine intake (a) Forest plot of analysis among different levels of iodine intake (UIC $<200 \mu \mathrm{g} / \mathrm{L}$ and UIC $\geq 200 \mu \mathrm{g} / \mathrm{L}$ ). (b) Forest plot of analysis among different levels of iodine intake (UIC $<100 \mu \mathrm{g} / \mathrm{L}$ and UIC $100-200 \mu \mathrm{g} / \mathrm{L}$ ). UIC, urinary iodine concentration; CI, confidence interval; M-H, Mantel-Haenszel; BRAF mutation, BRAFV600E mutation.

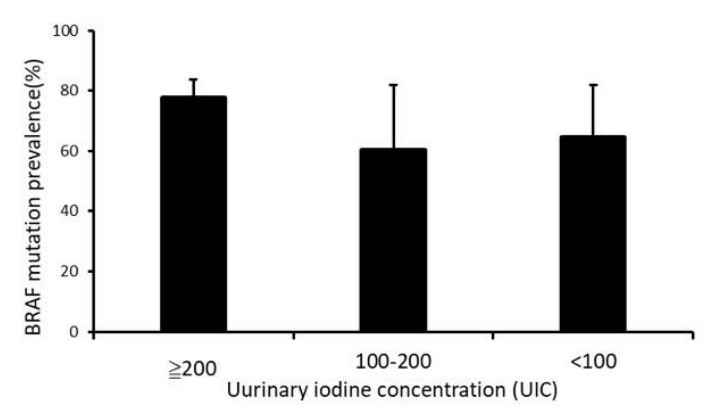

\begin{tabular}{cccc} 
& UIC $\geqq 200$ & UIC100-200 & UIC $<100$ \\
\hline Guan 2009 & 69.23 & 52.53 & 54.78 \\
Kim 2018 & 79.26 & 81.63 & 83.87 \\
Voung 2016 & 82.09 & & 83.02 \\
Liu 2014 & & 73.27 & 49.51 \\
Pellegriti 2009 & & 33.17 & 51.89 \\
Lee 2018 & 80.48 & & \\
\hline Mean & 77.76 & 60.15 & 64.61 \\
SD & 5.81 & 21.75 & 17.29
\end{tabular}

Figure 3. Statistical analysis among different levels of iodine nutritional status. UIC, urinary iodine concentration. 


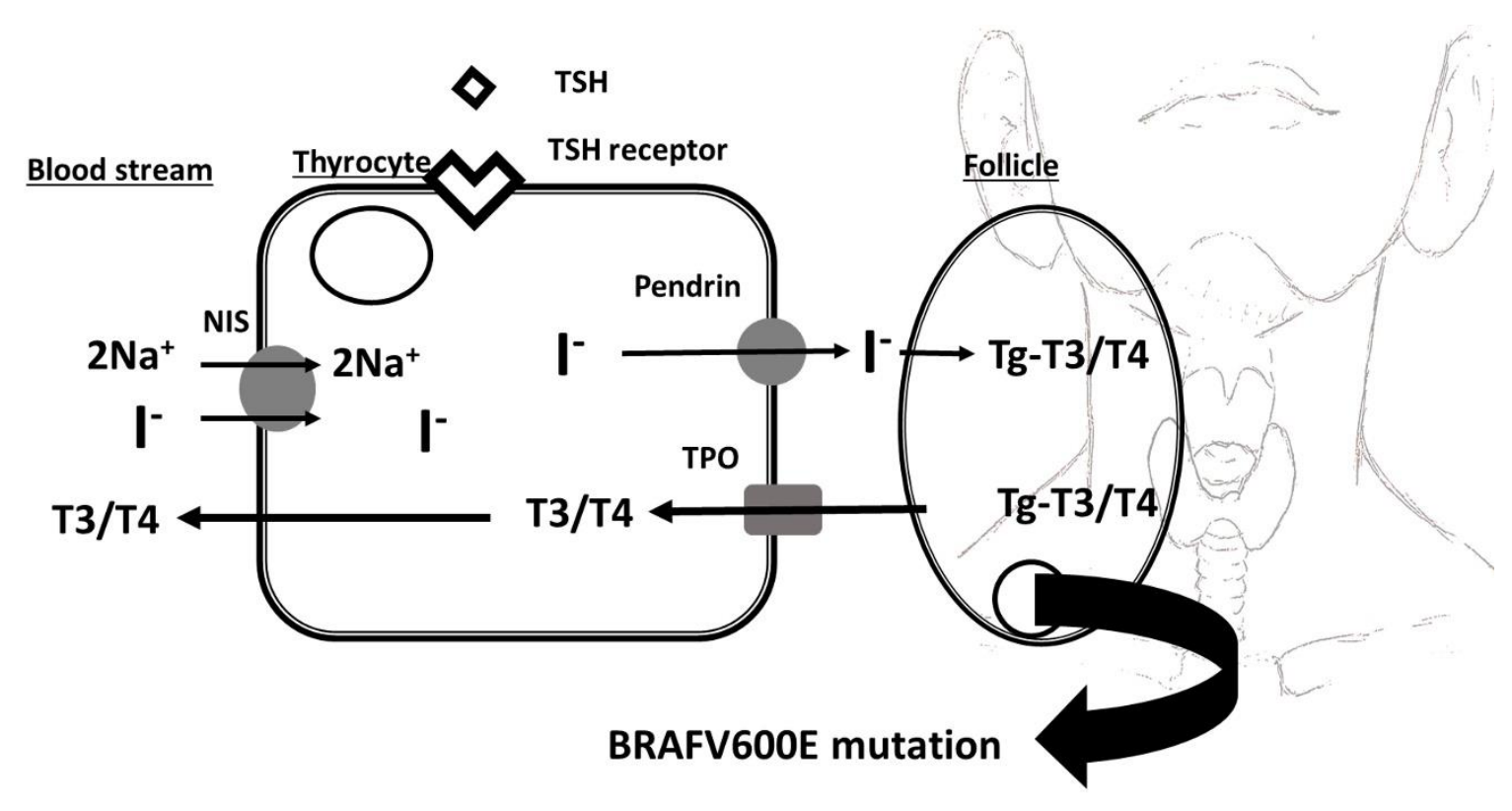

Figure 4. Schematic representation of iodide metabolism. TSH, thyroid stimulating hormone; BRAF, the b-raf oncogene; ERK, the extracellular-signal-regulated kinase, also known as the Ras-Raf-MEK-ERK pathway; Tg, Thyroglobulin; T3, triiodothyronine; T4, thyroxine; NIS, sodium/iodine symporter; TPO, thyroperoxidase..

\section{Discussion}

In the past 10 years, many previous researches have been reported that the important role of BRAFV600E mutation in PTC, but few studies discuss the related of nutrition iodine intake status and BRAFV600E mutation prevalence in PTC. Hence, to further evaluate the role of risk marker, iodine, in BRAFV600E mutation in PTC might be important to prevent the disease and progression. However, how the level of iodine intake influences BRAFV600E mutation in PTC remains controversial. Although neither relatively high nor low iodine intake showed a significant change in the prevalence of BRAF mutation between groups.

The results indicated that - abnormally - iodine intake may play a role, at least to some extent, in the tumorigenesis of PTC and influence the increase of BRAFV600E mutations in PTC, but a deficient or sufficient dietary iodine intake may influence BRAFV600E gene mutation through different pathways. A study from South Korea reported that both deficient and excessive dietary iodine intake may lead to thyroid disease or dysfunction, which exhibited U-shaped curves [3]. High iodine intake was reported to be associated with the prevalence of the BRAFV600E mutation in China [8], but another report stated there was no statistical difference in BRAFV600E mutation prevalence between Japanese and Vietnamese residents [9]. Additionally, in a study from Saudi Arabia, the mutation rate of the Ras oncogene, a BRAF upstream gene mutation, was significantly higher in the iodine-deficient area, being 85 versus $17 \%$ in the adenomas, and 50 versus $10 \%$ in the follicular carcinomas, but was not found in papillary carcinomas [16]. In fact, the increase in prevalence of BRAFV600E mutation is associated with abnormal dietary iodine intake and an increased proportion of PTC, which have been reported in different geographical areas $[2,8,10]$. Hence, the difference in geographical areas, diet preference, and culture of the population may be major variables in this study that affected the analysis results.

A schematic of iodine metabolism in the thyroid is presented in Fig. 4. The thyroid gland uses iodine, which is obtained from water or foods, to synthesize thyroid hormones, 
which are thyroxine (T4) and triiodothyronine (T3) in thyroid follicular cells. The daily turnover of iodine by the thyroid is approximately 60-95 $\mu \mathrm{g}$ in heathy adults. Normally, $70 \%-80 \%$ of iodine is in the thyroid. Most forms of iodine are absorbed in the stomach and small intestine [17]. In the membrane of thyroid cells, the sodium/iodine symporter (NIS), which is an integral membrane glycoprotein, mediates iodine transport into the thyroid follicular cells to induce thyroid hormone biosynthesis, decreasing in thyroid follicular cells to produce T3 and T4 [18]. Iodine from the degradation of T3 and T4 that re-enters the circulation is eventually excreted in the urine, and in addition, iodide could also induce down-regulation of NIS in thyroid cells [19].

BRAFV600E mutation can severely compromise expression of various iodide-metabolizing genes. It is a critical molecular marker for the prognostic evaluation and clinical management of PTC and has a strong association with iodine metabolism, as reliably detected in cells aspirated from a thyroid nodule using a fine needle [20]. In a previous study, BRAFV600E mutation in PTC was reported to be associated with the abnormal expression of key genes involved in iodine metabolism [21]. A large cohort study in China investigated the association between iodine intake and BRAF mutation in different cities. The results revealed that lymph node metastasis and disease progression were significantly associated with BRAFV600E mutation and high iodine intake [8]. A study of recurrent PTC indicated that $77.8 \%$ of tumors were found to have BRAFV600E mutation, and the results suggested that recurrent PTC is significantly associated with a predominant BRAFV600E mutation [22].

The pathway between BRAFV600E and PTC is complicated. A Brazilian study also suggested that NIS gene suppression was found in conventional PTC, which is related to BRAFV600E mutation [23]. It might indicate that the BRAFV600E mutation was modulated by NIS in PTC.

Although the molecular pathways of BRAFV600E mutations in PTC are numerous and complicated, a study reported that they can influence the function of NIS [24]. Moreover, in vitro results of research indicated that under the condition of BRAFV600E expression, suppressed iodine metabolizing genes were found in thyroid cell lines [25]. A study recruited a cohort of Taiwanese patients with PTC and compared between BRAFV600E mutated and wild-type groups, demonstrating that BRAFV600E-mutated PTC involved 27 exclusive pathways in PTC [26], therefore, to more clarify the role and underlying mechanism of NIS in BRAFV600E-mutated PTC in Taiwanese patients may be necessary in future.

RAS kinase belongs to a family of small G-proteins located on the inner surface of cell membranes. Among protein kinase, the BRAF gene serves as an immediate downstream effector of RAS. BRAF transmits signals from RAS to the mitogen-activated protein kinase (MAPK) pathway through mitogen-activated protein/extracellular signal-regulated kinase (ERK) kinase (MEK). Inhibition of MAPK/ERK pathway or suppress BRAFV600E by inhibitors or Small interfering RNA (siRNA) could restored the expression of the iodide-metabolizing related genes [24], These results suggest that the MAPK/ERK pathway may play a vital role between iodine and the BRAF gene. Therefore, on the basis of previous studies, BRAFV600E mutation can affect iodine metabolization; Future studies should explore the underlying mechanisms in the relationship between NIS and the MAPK/ERK pathway.

Compared with other meta-analyses in the healthy population, this study focused on BRAFV600E mutation in patients with PTC because compared with the healthy population, patients may have more consistent characteristics related to PTC. This can help correctly evaluate the effect of iodine on BRAFV600E mutation. However, similar ethnic 
backgrounds and biological characterizations must be considered to further clarify the association.

This study has some limitations. First, in the past 10 years, few related studies have investigated the issue at hand, and some of the included studies might not have adequately adjusted for potential confounding risk factors. High heterogeneity may be present when estimated by the I2 statistic if the number of studies is small, which was considered the main reason for the high heterogeneity in the present study. Second, in some of the included studies, the determination of UIC was based on previous results or published statistical data in the area, and not on direct data of participants. Third, the distribution of iodine nutrition varies from region to region, thus, some references have not included that surveys on high or low level of iodine populations. Thus, we separated the research groups and used the method of between analysis and statistical analysis to try to find clues as the basis for further research in the future. These may have led to misclassification and bias. However, as discussed previously, selection and bias are always possible. Therefore, to minimize bias, a comprehensive search strategy, two independent reviewers, and standardized eligibility criteria should be employed. Further research is obviously required but should be considered to the limitation of this study.

\section{Conclusions}

This study conducted preliminary research on dietary iodine intake and BRAFV600E mutation in patients with PTC. The results suggested that abnormal iodine intake could slightly influence the prevalence of BRAFV600E mutation in patients with PTC but no statistical difference. The iodine intake may significantly induce BRAFV600E gene mutation through different pathways in patients with PTC.

Despite the link between iodine intake and BRAF mutation, little empirical evidence exists for a direct relationship between the two factors of PTC. Clearly investigating the dietary iodine intake and BRAFV600E mutation in PTC seems necessary in the future. Further studies on the potential mechanisms underlying the associations between dietary iodine intake and BRAF mutation in PTC will provide additional insights into PTC. We anticipate that such work will generate critical findings in the field.

\section{References}

1. Lin JD, Fu SS, Chen JY, Lee CH, Chau WK, Cheng CW, Wang YH, Lin YF, Fang WF, Tang KT. Clinical Manifestations and Gene Expression in Patients with Conventional Papillary Thyroid Carcinoma Carrying the BRAF(V600E) Mutation and BRAF Pseudogene. Thyroid 2016, 26:691-704. https://doi.org/10.1089/thy.2015.0044

2. Hong AR, Lim JA, Kim TH, Choi HS, Yoo WS, Min HS, Won JK, Lee KE, Jung KC, Park DJ, Park YJ. The Frequency and Clinical Implications of the BRAF(V600E) Mutation in Papillary Thyroid Cancer Patients in Korea Over the Past Two Decades. Endocrinol Metab (Seoul) 2014, 29:505-513. https://doi.org/10.3803/EnM.2014.29.4.505

3. Kim HJ, Park HK, Byun DW, Suh K, Yoo MH, Min YK, Kim SW, Chung JH. Iodine intake as a risk factor for BRAF mutations in papillary thyroid cancer patients from an iodine-replete area. Eur J Nutr 2018, 57:809-815. https://doi.org/10.1007/s00394-016-1370-2

4. Tang KT, Pan WH, Wang FF, Lin JD, Won GS, Chau WK, Lin HD, Hsieh YT. Iodine status of Taiwanese children before the change in national salt iodization policy: a retrospective study of the nutrition and health survey in Taiwan 2001-2002. Asia Pac J Clin Nutr 2014, 23:481-487. https://doi.org/10.6133/apjen. 2014.23.3.20

5. Tang KT, Wang FF, Pan WH, Lin JD, Won GS, Chau WK, Lin HD, Hsieh YT.Iodine status of adults in Taiwan 2005-2008, 5 years after the cessation of mandatory salt iodization. J Formos Med Assoc 2016, 115:645-651. https://doi.org/10.1016/j.jfma.2015.06.014

6. Wang FF, Tang KT, Pan WH, Won JG, Hsieh YT, Huang CJ. Iodine Status of Taiwanese Population in 2013: 10 Years After Changing From Mandatory to Voluntary Salt Iodization. Food Nutr Bull 2018, 39:75-85. https://doi.org/10.1177/0379572117738883

7. Liu RT, Chen YJ, Chou FF, Li CL, Wu WL, Tsai PC, Huang CC, Cheng JT. No correlation between BRAFV600E mutation and clinicopathological features of papillary thyroid carcinomas in Taiwan. Clin Endocrinol (Oxf) 2005, 63:461-466. https://doi.org/10.1111/j.1365-2265.2005.02367.x

8. Guan H, Ji M, Bao R, Yu H, Wang Y, Hou P, Zhang Y, Shan Z, Teng W, Xing M. Association of high iodine intake with the T1799A BRAF mutation in papillary thyroid cancer. J Clin Endocrinol Metab 2009, 94:1612-1617. https://doi.org/ 10.1210/jc.2008-2390

9. Vuong HG, Kondo T, Oishi N, Nakazawa T, Mochizuki K, Inoue T, Tahara I, Kasai K, Hirokawa M, Tran TM, Katoh R. Genetic alterations of differentiated thyroid carcinoma in iodine-rich and iodine-deficient countries. Cancer medicine 2016, 5:1883-1889. https://doi.org/10.1002/ cam4.781 
10. Pellegriti G, De Vathaire F, Scollo C, Attard M, Giordano C, Arena S, Dardanoni G, Frasca F, Malandrino P, Vermiglio F, et al. Papillary thyroid cancer incidence in the volcanic area of Sicily. J Natl Cancer Inst 2009, 101:1575-1583. https://doi.org/10.1093/jnci/djp354

11. Liu X, Qu S, Liu R, Sheng C, Shi X, Zhu G, Murugan AK, Guan H, Yu H, Wang Y, et al. TERT promoter mutations and their association with BRAF V600E mutation and aggressive clinicopathological characteristics of thyroid cancer. J Clin Endocrinol Metab 2014, 99:E1130-1136. https://doi.org/10.1210/jc.2013-4048

12. Lee JH, Song RY, Yi JW, Yu HW, Kwon H, Kim SJ, Chai YJ, Choi JY, Moon JH, Lee KE, et al. Case-Control Study of Papillary Thyroid Carcinoma on Urinary and Dietary Iodine Status in South Korea. World J Surg 2018, 42:1424-1431. https://doi.org/10.1007/s00268-017-4287-x.

13. UNICEF: A review of the nutrition situation in vietnam 2009-2010.: UNICEF Vietnam, Ha Noi.; 2011. http://www.wpro.who.int/vietnam/publications/nutritionreview/en/

14. Katagiri R, Asakura K, Uechi K, Masayasu S, Sasaki S. Iodine Excretion in 24-hour Urine Collection and Its Dietary Determinants in Healthy Japanese Adults. Journal of epidemiology 2016, 26:613-621. https:// doi.org/10.2188/jea.JE20150245

15. Belfiore A, La Rosa GL, La Porta GA, Giuffrida D, Milazzo G, Lupo L, Regalbuto C, Vigneri R. Cancer risk in patients with cold thyroid nodules: relevance of iodine intake, sex, age, and multinodularity. Am J Med 1992, 93:363-369.

16. Shi YF, Zou MJ, Schmidt H, Juhasz F, Stensky V, Robb D, Farid NR. High rates of ras codon 61 mutation in thyroid tumors in an iodide-deficient area. Cancer Res 1991, 51:2690-2693.

17. Zimmermann MB. Iodine deficiency. Endocr Rev 2009, 30:376-408. https://doi.org/ 10.1210/er.2009-0011

18. Eskandari S, Loo DD, Dai G, Levy O, Wright EM, Carrasco N. Thyroid Na+/I- symporter. Mechanism, stoichiometry, and specificity. J Biol Chem 1997, 272:27230-27238. https://doi.org/10.1074/jbc.272.43.27230

19. Uyttersprot N, Pelgrims N, Carrasco N, Gervy C, Maenhaut C, Dumont JE, Miot F. Moderate doses of iodide in vivo inhibit cell proliferation and the expression of thyroperoxidase and Na+/I- symporter mRNAs in dog thyroid. Mol Cell Endocrinol 1997, 131:195-203.

20. Jin L, Sebo TJ, Nakamura N, Qian X, Oliveira A, Majerus JA, Johnson MR, Lloyd RV. BRAF mutation analysis in fine needle aspiration (FNA) cytology of the thyroid. Diagn Mol Pathol 2006, 15:136-143. https://doi.org/10.1097/01. pdm.0000213461.53021.84

21. Durante C, Puxeddu E, Ferretti E, Morisi R, Moretti S, Bruno R, Barbi F, Avenia N, Scipioni A, Verrienti A, et al. BRAF mutations in papillary thyroid carcinomas inhibit genes involved in iodine metabolism. J Clin Endocrinol Metab 2007, 92:2840-2843. https://doi.org/10.1210/jc.2006-2707.

22. Henderson YC, Shellenberger TD, Williams MD, El-Naggar AK, Fredrick MJ, Cieply KM, Clayman GL. High rate of BRAF and RET/PTC dual mutations associated with recurrent papillary thyroid carcinoma. Clin Cancer Res 2009, 15:485-491. https://doi.org/10.1158/1078-0432.CCR-08-0933.

23. Oler G, Cerutti JM. High prevalence of BRAF mutation in a Brazilian cohort of patients with sporadic papillary thyroid carcinomas: correlation with more aggressive phenotype and decreased expression of iodide-metabolizing genes. Cancer 2009, 115:972-980. https://doi.org/10.1002/cncr.24118.

24. Riesco-Eizaguirre G, Gutierrez-Martinez P, Garcia-Cabezas MA, Nistal M, Santisteban P. The oncogene BRAF V600E is associated with a high risk of recurrence and less differentiated papillary thyroid carcinoma due to the impairment of Na+/I- targeting to the membrane. Endocr Relat Cancer 2006, 13:257-269. https:// doi.org/10.1677/erc.1.01119

25. Mitsutake N, Knauf JA, Mitsutake S, Mesa C, Jr., Zhang L, Fagin JA. Conditional BRAFV600E expression induces DNA synthesis, apoptosis, dedifferentiation, and chromosomal instability in thyroid PCCL3 cells. Cancer Res 2005, 65:2465-2473. https://doi.org/10.1158/0008-5472.can-04-3314

26. Chang CC, Chang YS, Huang HY, Yeh KT, Liu TC, Chang JG. Determination of the mutational landscape in Taiwanese patients with papillary thyroid cancer by whole-exome sequencing. Hum Pathol 2018, 78:151-158. https://doi.org/10.1016/j.humpath.2018.04.023 